Article

\title{
An Improved Approach for Soil Moisture Estimation in Gully Fields of the Loess Plateau Using Sentinel-1A Radar Images
}

\author{
Shanchuan Guo ${ }^{1,2,3} \mathbb{D}^{-}$, Xuyu Bai ${ }^{1,2}$, Yu Chen ${ }^{3,4} \mathbb{D}^{-}$, Shaoliang Zhang ${ }^{3}{ }^{\mathbb{D}}$, Huping Hou ${ }^{3}$, \\ Qianlin Zhu ${ }^{5}$ and Peijun Du 1,2,* \\ 1 Key Laboratory for Satellite Mapping Technology and Applications of State Administration of Surveying, \\ Mapping and Geoinformation of China, Nanjing University, Nanjing 210023, China; \\ gsccn@outlook.com (S.G.); baixy26@163.com (X.B.) \\ 2 School of Geography and Ocean Science, Nanjing University, Nanjing 210023, China \\ 3 School of Environment Science and Spatial Informatics, China University of Mining and Technology, \\ Xuzhou 221116, China; chenyurs@gmail.com (Y.C.); slzhang@cumt.edu.cn (S.Z.); hphou@163.com (H.H.) \\ 4 Key Laboratory for Land Environment and Disaster Monitoring of NASG, China University of Mining \\ and Technology, Xuzhou 221116, China \\ 5 Low Carbon Energy Institute, China University of Mining and Technology, Xuzhou 221008, China; \\ zhuql@cumt.edu.cn \\ * Correspondence: dupjrs@gmail.com; Tel.: +86-159-0515-9291
}

Received: 21 January 2019; Accepted: 1 February 2019; Published: 10 February 2019

\begin{abstract}
As an essential ecological parameter, soil moisture is important for understanding the water exchange between the land surface and the atmosphere, especially in the Loess Plateau (China). Although Synthetic Aperture Radar (SAR) images can be used for soil moisture retrieval, it is still a challenge to mitigate the impacts of complex terrain over hilly areas. Therefore, the objective of this paper is to propose an improved approach for soil moisture estimation in gully fields based on the joint use of the Advanced Integral Equation Model (AIEM) and the Incidence Angle Correction Model (IACM) from Sentinel-1A observations. AIEM is utilized to build a simulation database of microwave backscattering coefficients from various radar parameters and surface parameters, which is the data basis for the retrieval modeling. IACM is proposed to correct the deviation between the local incidence angle at the scatterer and the radar viewing angle. The study area is located in the Loess Plateau of China, where the main land cover is mostly bare land and the terrain is complex. The Sentinel-1A SAR data in C-band with dual polarization acquired on October 19th, 2017 was adopted to extract the VV\&VH polarimetric backscattering coefficients. The in situ measurements of soil moisture were collected on the same day of the SAR acquisition, for evaluating the accuracy of the SAR-derived soil moisture. The results showed that, firstly, the estimated soil moisture with volumetric content between $0 \%$ and $20 \%$ was in the majority. Subsequently, both the RMSE of estimation values $(0.963 \%)$ and the standard deviation of absolute errors $(0.957 \%)$ demonstrated a good accuracy of the improved approach. Moreover, the evaluation of IACM confirmed that the improved approach coupling IACM and AIEM was more efficient than employing AIEM solely. In conclusion, the proposed approach has a strong ability to estimate the soil moisture in the gully fields of the Loess Plateau from Sentinel-1A data.
\end{abstract}

Keywords: soil moisture estimation; AIEM; IACM; Sentinel-1A; the Loess Plateau

\section{Introduction}

Soil moisture, a basic parameter of water cycle process in the ecosystem, plays a crucial role in multifarious applications such as ecological monitoring, hydrological cycle simulation, and climate 
change analysis [1-4]. Particularly in the Loess Plateau area (China), with the semi-arid environment and the fragile ecosystem, a comprehensive knowledge of the status of soil moisture helps to enhance the effectiveness of the ecological protection or restoration engineering, such as soil-water conservation, land reclamation, and vegetation restoration, thus making the soil moisture measurement more necessary [5-9]. However, in situ measurements of soil moisture are often difficult (or impossible) to access in the Loess Plateau gully fields because of the complex terrain and unstable slope. Also, the traditional field investigation methods can only provide local discrete information on the soil moisture. Estimation of the soil moisture at the regional scale would be better accomplished using remote sensing technology. Both optical and microwave remote sensing have been evidenced to be able to retrieve soil moisture, but optical images are strongly limited by the clouds and solar radiation conditions [10-15]. With more and more spaceborne SAR missions implementing and operating successfully, the active microwave remote sensing generally referring to SAR, has demonstrated its excellent potential to estimate the soil moisture due to the high sensitivity of backscattered radar signal to surface characteristics, together with the capacity for all-weather and all-time sensing [16-21].

Three basic types of microwave modeling methods for soil moisture retrieval from SAR radar images have been previously proposed: the empirical models [22-25], the semi-empirical models [26-28], and the theoretical models [29-35]. The empirical and semi-empirical models investigate the mathematical relations between radar backscattering coefficients and surface parameters based on a large number of in situ measurements, which usually provides a few fitted parameters that derived from the particular fields [36]. In other words, these models only perform well on similar surface profiles from the same SAR sensors, but have limitations when the parameters are unsuited to the particular conditions. As one of the basic theoretical models, the Integral Equation Model (IEM) has promoted the model parameters of surface profiles into a wider domain, successfully bridging the gap between the Small Perturbation Model (SPM) and the classical Kirchhoff [29,30], but it still has several flaws resulting from its assumptions. To optimize it, the Advanced IEM (AIEM) operates on the multiple scattering terms expression and the Fresnel reflection coefficients improvement, resulting in better microwave emissivity simulation for a wide range of roughness scales [30-33]. Considering that topographic parameters such as slope and aspect influence the return backscattered signal of SAR [37], soil moisture retrieval based on AIEM simulation in gully fields can be less reliable than that in the plains. Therefore, understanding and adequately incorporating the impacts of complex terrain are essential issues of soil moisture retrieval in gully fields of the Loess Plateau.

Although many studies on soil moisture estimation over bare soil, vegetation land, grassland, and agricultural soil have been reported [38-42], there is a dearth of research in gully fields. To explore the potentiality of soil moisture retrieval in gully fields from SAR data, this paper proposed an improved approach which utilizes the Incidence Angle Correction Model (IACM) to mitigate the impacts of topography on soil moisture modeling using remote sensing. The local incidence angle, rather than the radar viewing angle, is the exact parameter that can represent the reality in the gully fields. Therefore, IACM is used to compute the local incidence angle, which plays an important role in the basic retrieval model established by AIEM simulation database. Previous studies on soil moisture retrieval often adopt SAR data in C-band due to its high accessibility from several spaceborne SAR sensors (ERS-1/2, ENVISAT ASAR, and RADARSAT-1/2) [21,43-48]. Particularly in recent years, Sentinel-1A, launched by the European Space Agency (ESA), offers a finer spatiotemporal resolution data with totally open-access, greatly promoting the research and application of C-band SAR data for soil moisture estimation [49-51]. In conclusion, the main contribution of this paper is to broaden the application of soil moisture estimation from Sentinel-1A data to the Loess Plateau, and furthermore provide references for soil moisture estimation in other mountainous areas.

The organization of this paper is as follows: After a brief introduction in this section, Section 2 introduce the data set and study area in the Loess Plateau. Section 3 describes the methods for simulation process, the numerical analysis for retrieval modeling, and the local incidence correction. 
The results and discussion of the soil moisture estimation are presented in Sections 4 and 5, respectively. Concluding remarks are provided in Section 6.

\section{Study Area and Datasets}

\subsection{Study Area and In Situ Measurements}

The study area, which belongs to the middle part of the Loess Plateau shown in Figure 1a, is located in Jingbian County, Shaanxi Province, China, with a central latitude of $37^{\circ} 22^{\prime} \mathrm{N}$ and a central longitude of $108^{\circ} 58^{\prime} \mathrm{E}$. The region has a surface of about $110 \mathrm{~km}^{2}$ and is characterized by rugged terrain and complicated gullies with elevation varying from $1200 \mathrm{~m}$ and $1700 \mathrm{~m}$. In addition, the region provides a representative of the typical semi-arid circumstance with $455.76 \mathrm{~mm} / \mathrm{a}$ precipitation and $1510.14 \mathrm{~mm} / \mathrm{a}$ potential evapotranspiration, as shown in Table 1 . The above-mentioned situations result in the land type mostly manifesting as sparse meadows and bare land, as shown in Figure $1 \mathrm{~b}$. Figure 1c shows the scenery of the region where bare land becomes the leading land type during the dry season from October to May (the following year), largely because of the continental monsoon climate.

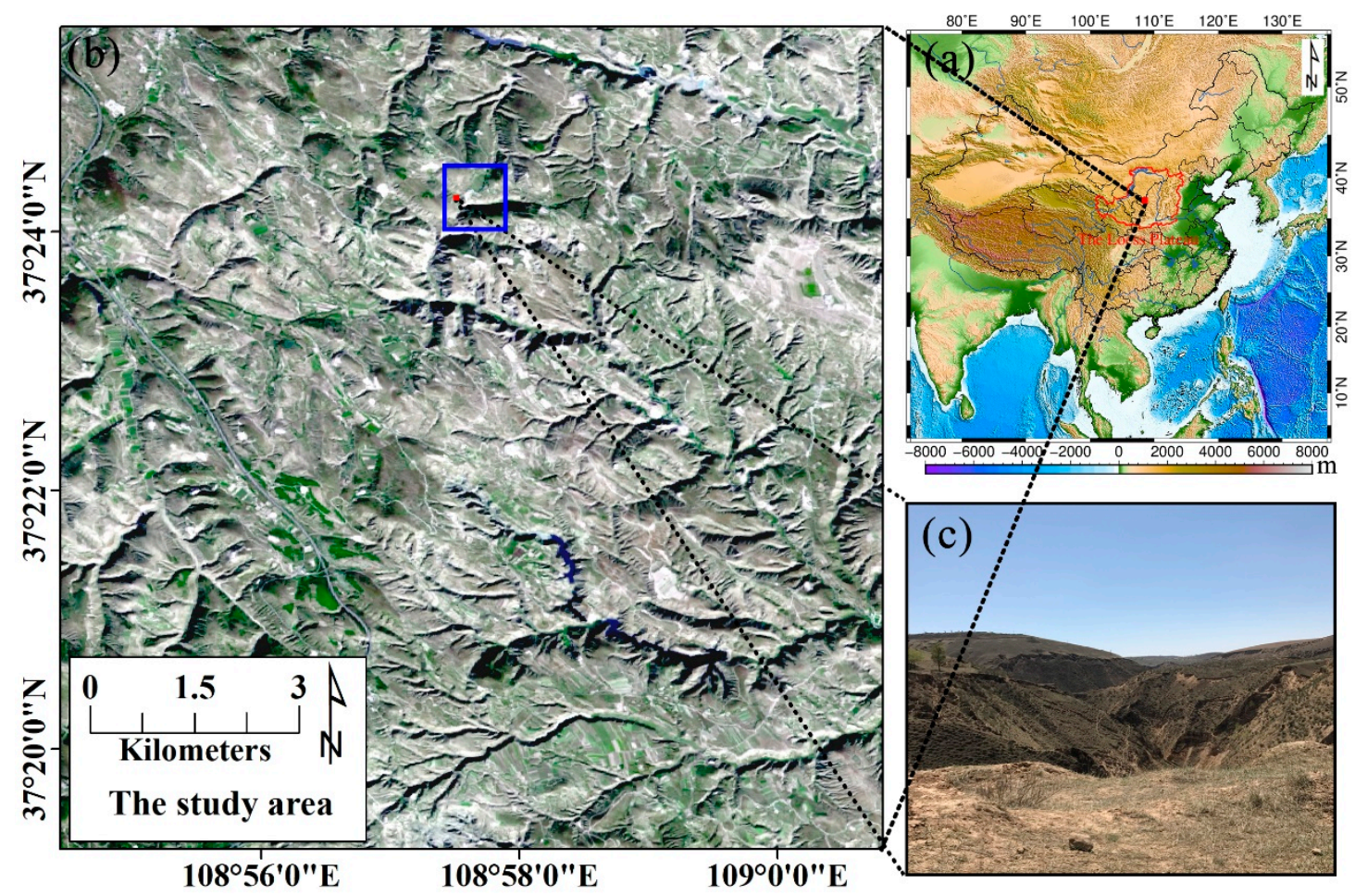

Figure 1. Information of the study area: (a) Location of the study area in the Loess Plateau, outlined by the red polygon. (b) False color composite image (with $R, G, B=$ band $6,5,4$ ) from Landsat-8 Operational Land Imager (OLI) of the study area, acquired on September 28th, 2016. The blue rectangle indicates the area with in situ measurements. (c) Surface scenery photo taken on October 19th, 2017.

To evaluate the accuracy of the soil moisture estimation, a network with sampling spacing larger than the pixel spacing of SAR images was constructed as 43 in situ measurements placed within the area shown in Figure 2a, whose border is marked in blue in Figure 1b. Within 2 hours before the acquisition time of Sentinel-1A (10:45 a.m. on October 19th, 2017, GMT), the volumetric soil moisture of the sampling sites was measured by the soil moisture sensing probe at a depth of approximately $5 \mathrm{~cm}$, which is most closely related to the sensing ability of the C-band SAR data [43,52,53]. At each sampling site, soil moisture measurement below the surface 0 to $5 \mathrm{~cm}$ was derived from the average of 9 points formed as the double cross pattern (the shape of the British "Union Jack") with $1 \mathrm{~m}$ spacing. 
The soil moisture results of 43 in situ measurements with approximately $\pm 1 \%$ volumetric precision are presented in Figure $2 b$.

Table 1. Seasonal values of precipitation and potential evapotranspiration in the study area.

\begin{tabular}{cccccc}
\hline Meteorological Data & Spring & Summer & Autumn & Winter & Annual \\
\hline Precipitation $(\mathrm{mm})$ & 73.38 & 235.66 & 131.74 & 14.98 & 455.76 \\
$\begin{array}{c}\text { Potential } \\
\text { evapotranspiration }(\mathrm{mm})\end{array}$ & 527.54 & 533.58 & 285.34 & 163.68 & 1510.14 \\
\hline
\end{tabular}

${ }^{1}$ Precipitation and potential evapotranspiration data were sourced from Jingbian meteorological station (No. 53735, China) from 2013 to 2017.
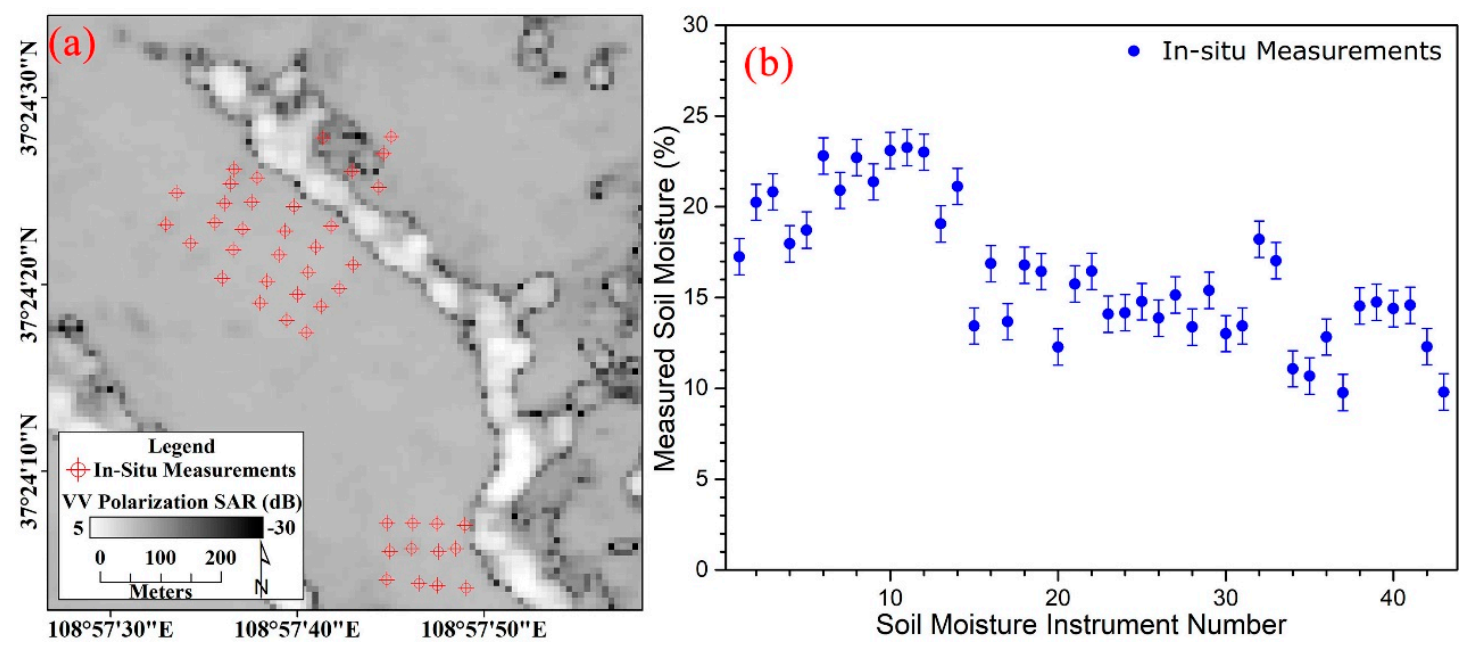

Figure 2. (a) Location of the in situ measurements plotted on the Sentinel-1A VV polarization map in $\mathrm{dB}$. The spatial extent is indicated by the blue rectangle in Figure 1b; (b) The soil moisture (\% volume) of the in situ measurements. The error bars $( \pm 1 \%)$ were dependent on the accuracy of soil moisture instrument.

\subsection{Remote Sensing Datasets}

The SAR data were acquired by Sentinel-1A $(5.405 \mathrm{GHz})$ in interferometric wide swath (IW) mode with dual polarization (VV-VH) on October 19th, 2017 (https://scihub.copernicus.eu/). The level-1 Ground Range Detected (GRD) products, which had been projected to ground range using the Earth ellipsoid model WGS84 with approximately square pixel spacing of $10 \mathrm{~m}$, were used to extract radar backscattering coefficients. The pixel value of the GRD products represents only the detected amplitude since the phase information has been discarded. Moreover, all bursts in all sub-swaths of the products had been seamlessly merged to form a single and contiguous ground range image per polarization.

Before further information extraction and image analysis, the GRD Sentinel-1A images were preprocessed. The preprocessing involved radiometric operation with respect to calibration and terrain flattening [54], thermal noise removal, speckle filter (refined Lee filter), SAR mosaic, and radiometric normalization, was implemented using the Sentinel Application Platform (SNAP, http:/ /step.esa.int/ main/download/). The preprocessed results were mapped as Figure 3 shown.

The Digital Surface Model (DSM) data collected for the topographic parameters inversion were AW3D30 products (http:/ /www.eorc.jaxa.jp/ALOS/en/aw3d30/) with a horizontal resolution of $30 \mathrm{~m}$ mesh and a height accuracy of $5 \mathrm{~m}$, released by Japan Aerospace Exploration Agency (JAXA). The products had mapped the land terrains through the utilization of 3 million scene archives acquired by the PRISM sensor on the Advanced Land Observing Satellite (ALOS) from 2006 to 2011. Figure 3c provided the topographic map in the study area generated from AW3D 30 products. 

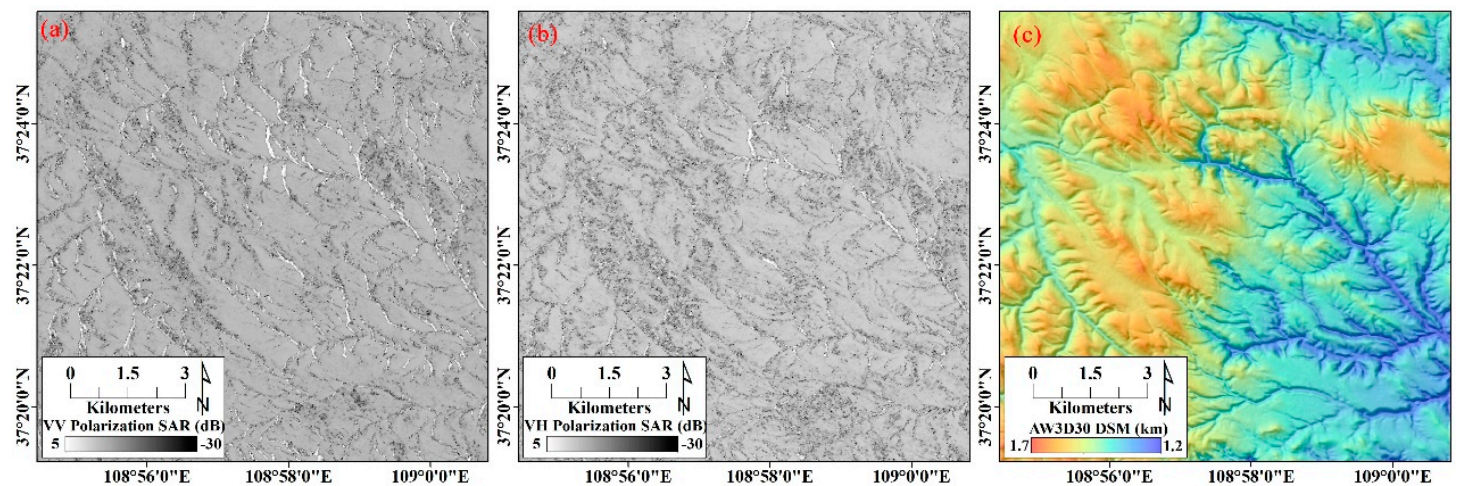

Figure 3. Remote sensing datasets of the study area: (a) VV polarimetric backscattering coefficients derived from GRD Sentinel-1A products; (b) VH polarimetric backscattering coefficients derived from GRD Sentinel-1A products; (c) the digital surface model from AW3D30 DSM products.

\section{Methodology}

As one of the analytical physical models that are most widely used, AIEM is employed for simulating the radar backscattering coefficients at various surface parameters over the study area. Considering that the AIEM had limited capability for dealing with the effect of complex topography, we proposed an improved retrieval approach to estimate soil moisture using Sentinel-1A radar data. The primary innovation of this approach is to append IACM into the preliminary retrieval model established by the simulation database, which efficiently mitigates the impacts from topographic factors. The process flow of soil moisture estimation is presented in Figure 4, and the detailed descriptions are introduced in the following sections.

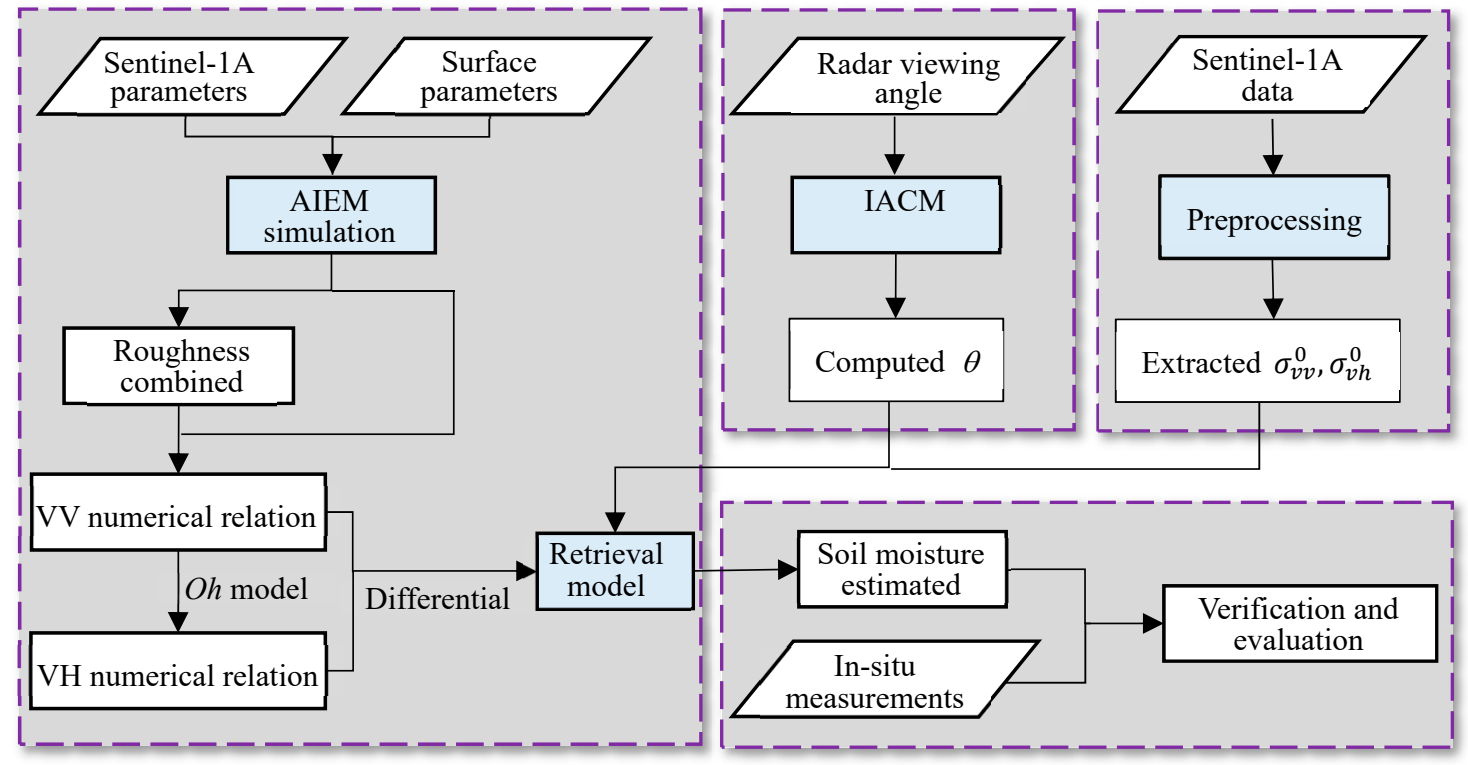

Figure 4. Flowchart for the soil moisture retrieval using the improved approach. $\theta$ is the local incidence angle at the scatterer. $\sigma_{v v}^{0}, \sigma_{v h}^{0}$ are the backscattering coefficients from VV polarization and $\mathrm{VH}$ polarization, respectively.

\subsection{Surface Roughness Parameters Combination Based on AIEM Simulation}

Based on the IEM proposed by Fung et al. [29], Chen and Wu proposed an improved model, referred to as AIEM, by replacing the Fresnel reflection coefficients with a transition function for solving the discontinuities in surface roughness and permittivity. The good performance of AIEM in simulating the backscattering coefficients has been previously addressed [31-33]. Therefore, the AIEM 
was adopted in this study to simulate the radar backscattering coefficients from the configuration parameters of Sentinel-1A SAR sensor. For establishing a simulated database, the input parameters of AIEM is set as shown in Table 2.

Table 2. Parameter setting of AIEM.

\begin{tabular}{cccc}
\hline Parameters & Minimum & Maximum & Interval \\
\hline Incidence angle $\theta\left(^{\circ}\right)$ & 10 & 70 & 1 \\
Soil moisture $M_{v}(\%)$ & 5 & 35 & 1 \\
Root mean square height $s(\mathrm{~cm})$ & 0.2 & 4 & 0.2 \\
Correlation length $l(\mathrm{~cm})$ & 2 & 40 & 2 \\
Frequency fre $(\mathrm{GHz})$ & \multicolumn{3}{c}{ 5.405 (Sentinel-1A sensor parameter) } \\
Auto-correlation function $(\mathrm{ACF})$ & \multicolumn{2}{c}{ Generalized power-law spectral density function } \\
\hline
\end{tabular}

The root mean square (RMS) height $s$ and the correlation length $l$ are the most used and basic parameters to describe surface roughness, which is essential for a fine simulation of the microwave scattering. According to in situ measurements, a data set of various surface roughness conditions was derived from the AIEM simulation database that satisfied the following settings: incidence angle $\theta$ is $35^{\circ}$; soil moisture $M_{v}$ is $20 \%$. In a multivariate regression analysis from the data set, the numerical relation between the backscattering coefficients and the RMS height $s$ and the correlation length $l$ was developed as:

$$
\sigma_{v v}^{0}=9.204 \ln (s)-5.314 \ln (l)+2.913,
$$

It is worth noting that an increase in the number of surface roughness parameters in a model will also increase the uncertainty of soil moisture retrieval, emphasizing the ill-posed problems in retrieval [55]. Therefore, we proposed a new description of surface roughness to unite the $s$ and the $l$ into only one comprehensive parameter, written as $R_{S}=\frac{s^{\sqrt{3}}}{l}$. In addition, then, Equation (1) was inverted to Equation (2).

$$
\sigma_{v v}^{0}=5.314 \ln R_{s}+2.913
$$

Figure 5 plots the simulated backscattered radar signal for the VV polarization in C-band $(5.405 \mathrm{GHz})$ at a $35^{\circ}$ incidence angle. A strong correlation between the backscattering coefficients and the surface roughness can be clearly observed, which indicates that it is an effective approach to taking into account $R_{S}$ as one of the model parameters for addressing the ill-posed problems in the retrieval.

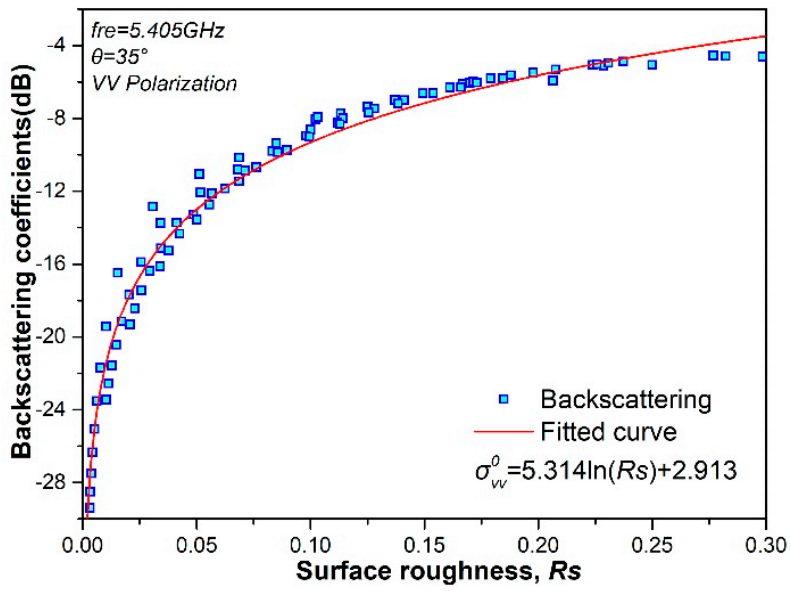

Figure 5. Backscattering coefficients $(\mathrm{dB})$ simulation in the VV polarization at $35^{\circ}$ incidence, presented using blue blocks. The red line represents the fitted curve. 


\subsection{Implementation of the Retrieval Model}

Over bare soil, the backscattering coefficient of the surface contribution $\sigma_{p p}^{0}$ (at the VV polarization, $p p=v v)$ for the co-polarization is expressed as [43,56]:

$$
\begin{gathered}
\sigma_{p p}^{0}=\frac{k^{2}}{2}\left|f_{p p}\right|^{2} e^{-4 k^{2} r m s^{2} \cos ^{2} \theta} \times \sum_{n=1}^{+\infty} \frac{\left(4 k^{2} r m s^{2} \cos ^{2} \theta\right)^{n}}{n !} W^{(n)}(2 k \sin \theta, 0) \\
+\frac{k^{2}}{2} \operatorname{Re}\left(f_{p p}^{*} F_{p p}\right) e^{-3 k^{2} r m s^{2} \cos ^{2} \theta} \times \sum_{n=1}^{+\infty} \frac{\left(4 k^{2} r m s^{2} \cos ^{2} \theta\right)^{n}}{n !} W^{(n)}(2 k \sin \theta, 0) \\
+\frac{k^{2}}{8}\left|F_{p p}\right|^{2} e^{-2 k^{2} r m s^{2} \cos ^{2} \theta} \times \sum_{n=1}^{+\infty} \frac{\left(k^{2} r m s^{2} \cos ^{2} \theta\right)^{n}}{n !} W^{(n)}(2 k \sin \theta, 0),
\end{gathered}
$$

where:

$$
\begin{gathered}
f_{v v}=\frac{2 R_{v}}{\cos \theta}, \\
F_{v v}=2 \frac{\sin ^{2} \theta}{\cos \theta}\left[\left(1-\frac{\varepsilon_{r} \cos ^{2} \theta}{u_{r} \varepsilon_{r}-\sin ^{2} \theta}\right)\left(1-R_{v}\right)+\left(1-\frac{1}{\varepsilon_{r}}\right)\left(1+R_{v}\right)^{2}\right], \\
R_{v}=\frac{\varepsilon_{r} \cos \theta-\sqrt{u_{r} \varepsilon_{r}-\sin ^{2} \theta}}{\varepsilon_{r} \cos \theta+\sqrt{u_{r} \varepsilon_{r}-\sin ^{2} \theta}}
\end{gathered}
$$

$R_{v}$ is the Fresnel coefficient; $u_{r}$ is the relative permittivity; Re is the real part of the complex number; $f_{p p}^{*}$ is the conjugate of the complex number $f_{p p} ; W^{(n)}$ is the Fourier transform of the $n$th power of the surface correlation function [20]. Volumetric soil moisture $M_{v}$ can be inverted from dielectric constant $\varepsilon_{r}$ by Dobson dielectric mixing model [57].

A statistical analysis of the AIEM simulation database indicated a strong logarithmic correlation between the backscattering coefficients and the soil moisture. As shown in Figure 6, the simulated backscattering coefficients are ideally correlated with the soil moisture at $30^{\circ}$ incidence angle with 0.25 $R_{S}$. This reveals that a numerical expression for $\sigma_{\mathrm{vv}}^{0}$ as a function of $M_{v}$ can be written as Equation (7) provided that the roughness parameter and the incidence angle are certain.

$$
\sigma_{v v}^{0}=A\left(R_{s}, \theta\right) \ln \left(M_{v}\right)+f\left(R_{s}, \theta\right),
$$

Analogously, the expression for $\sigma_{v v}^{0}$ as a function of $R_{s}$ can be given as Equation (8).

$$
\sigma_{v v}^{0}=B\left(M_{v}, \theta\right) \ln R_{s}+f\left(M_{v}, \theta\right),
$$

Therefore, while considering both the soil moisture and surface roughness with only incidence angle given, the numerical form for $\sigma_{v v}^{0}$ is expressed as:

$$
\sigma_{v v}^{0}=A(\theta) \ln \left(M_{v}\right)+B(\theta) \ln R_{s}+C(\theta)
$$

The backscattering coefficients for the VH polarization was simulated by adopting the cross-polarized ratio function that was previously proposed and reported by Oh et al [58-60]. After the VH-polarimetric backscattering coefficients $\sigma_{v h}^{0}$ had been computed, the numerical relation between cross-polarimetric backscattering coefficients and $R_{s}$ were computed as:

$$
\Delta \sigma_{v v}^{0}=D(\theta) \ln R_{s}+E(\theta)
$$

where $\Delta \sigma_{v v}^{0}$ is the differential backscattering coefficients of cross-polarization, which can be calculated as:

$$
\Delta \sigma_{v v}^{0}=\sigma_{v v}^{0}-\sigma_{v h}^{0}
$$


By combining Equation (10) and Equation (11), we eliminated the surface roughness parameter $R_{s}$. This process produces an obvious benefit that the retrieval model of soil moisture can be proposed as follows:

$$
\sigma_{v v}^{0}=A(\theta) \ln \left(M_{v}\right)+B(\theta) \cdot \frac{\sigma_{v v}^{0}-\sigma_{v h}^{0}-E(\theta)}{D(\theta)}+C(\theta)
$$

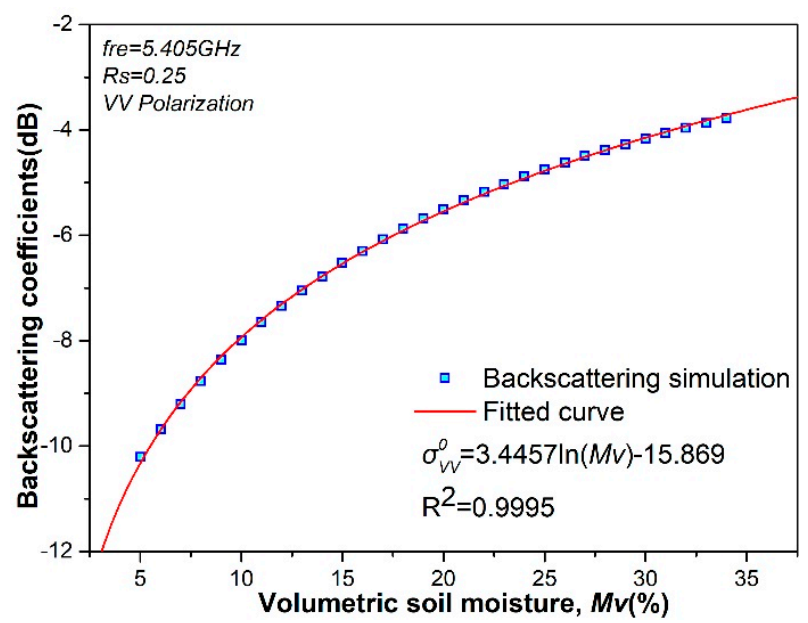

Figure 6. Backscattering coefficient $(\mathrm{dB})$ simulation in the $\mathrm{VV}$ polarization at $30^{\circ}$ incidence with 0.25 $R_{s}$, presented using blue blocks. The red line represents the fitted curve.

\subsection{The Local Incidence Angle Inversion by the IACM}

By understanding of the retrieval model of soil moisture, it is clear that the incidence angle $\theta$ at the ground scatterer is an essential parameter for the soil moisture estimation. The value of $\theta$ can refer directly to the radar viewing angle in the flat areas. However, as Figure 7 shows, in mountainous areas with rugged terrain, the local incidence angle at the scatterer is no longer adequately approximated by the value of radar viewing angle.

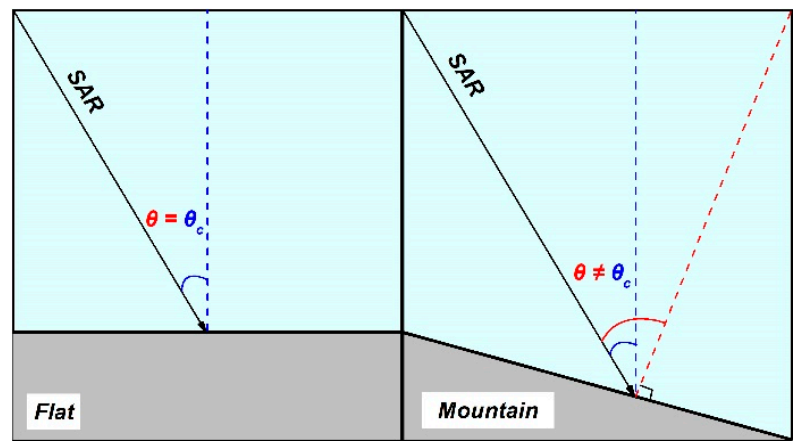

Figure 7. Diagram of the local incidence angle in flat and mountain areas. The red angle represents the local incidence angle $\theta$, and the blue angle indicates the radar viewing angle $\theta_{c}$.

Aiming for incidence angle correction, the IACM was calculated based on the spatial relationship between the spaceborne SAR and the surface scatterer:

$$
\theta=\theta_{c}+\text { slope } \cdot \cos \delta
$$


where $\theta_{c}$ is the radar viewing angle; slope represents the slope angle at the scatterer location, extracted from the AW3D DSM product; $\delta$ is the angle between the ground scatterer and the line of sight (LOS) as shown in Figure 8a, calculated as [61]:

$$
\delta=\operatorname{aspect} \pm\left(\beta-90^{\circ}\right),
$$

where the ascending mode corresponds to positive value, and the descending mode corresponds to negative value; aspect signifies the downslope direction, which is measured clockwise from $0^{\circ}$ (due north) to $360^{\circ}$ (again due north) [61]; $\beta$, the satellite heading angle, is equal to the deflection angle $\gamma$ as Figure $8 \mathrm{c}$ shown, calculated as [62]:

$$
\beta=\arcsin \frac{ \pm \cos \alpha}{\cos \xi}
$$

where $\alpha$ is the orbital inclination, obtained from spaceborne SAR configuration; $\xi$ is the latitude of the center of the SAR image; the positive value is employed for the ascending mode, and the negative for the descending.
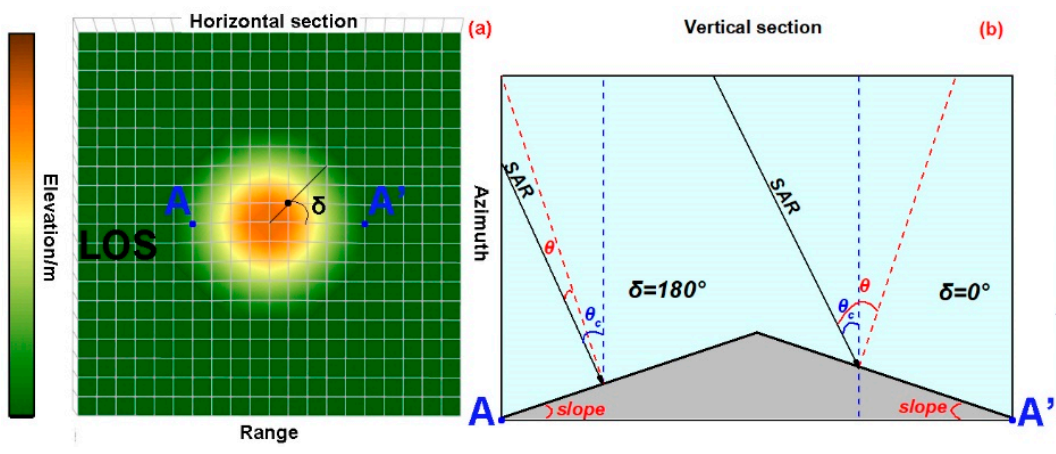

(b)

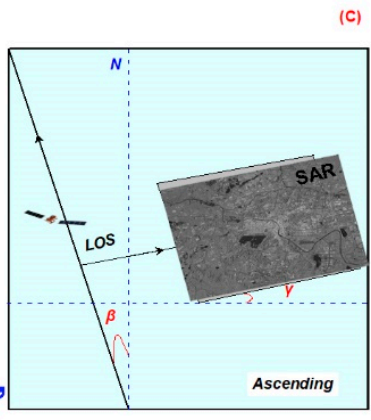

Figure 8. The schematic of the local incidence angle inversion: (a) the horizontal section of the ideal area with equal slope mountain and flat, where each cell corresponds to the sampling point of SAR; (b) the vertical section of the line $A A^{\prime}$ in Figure 8a, illustrating the relations between $\theta$ and $\theta_{c}$ while $\delta=0^{\circ}$ and $180^{\circ}$; (c) the heading angle $\beta$ of the satellite at the ascending mode with right side-looking imaging based on the Sentinel-1A configuration.

\section{Results}

\subsection{Solution for Coefficients in the Retrieval Model}

In the soil moisture retrieval model, expressed in Equation (12), there are still several coefficients of variables that need a definite numerical model for quantitative calculation, rather than only the notional expressions. Therefore, to observe the numerical relations between coefficients, i.e., $A(\theta)$, $B(\theta)$ and the incidence angle $\theta$, a large number of simulated backscattering coefficients based on AIEM were involved in the regression analysis and numerical modeling. The resultant numerical relations are presented in Figure 9, showing the response of the incidence angle $\theta$ to the function coefficients: $A(\theta), B(\theta), C(\theta), D(\theta), E(\theta)$, and the fitted curve. 

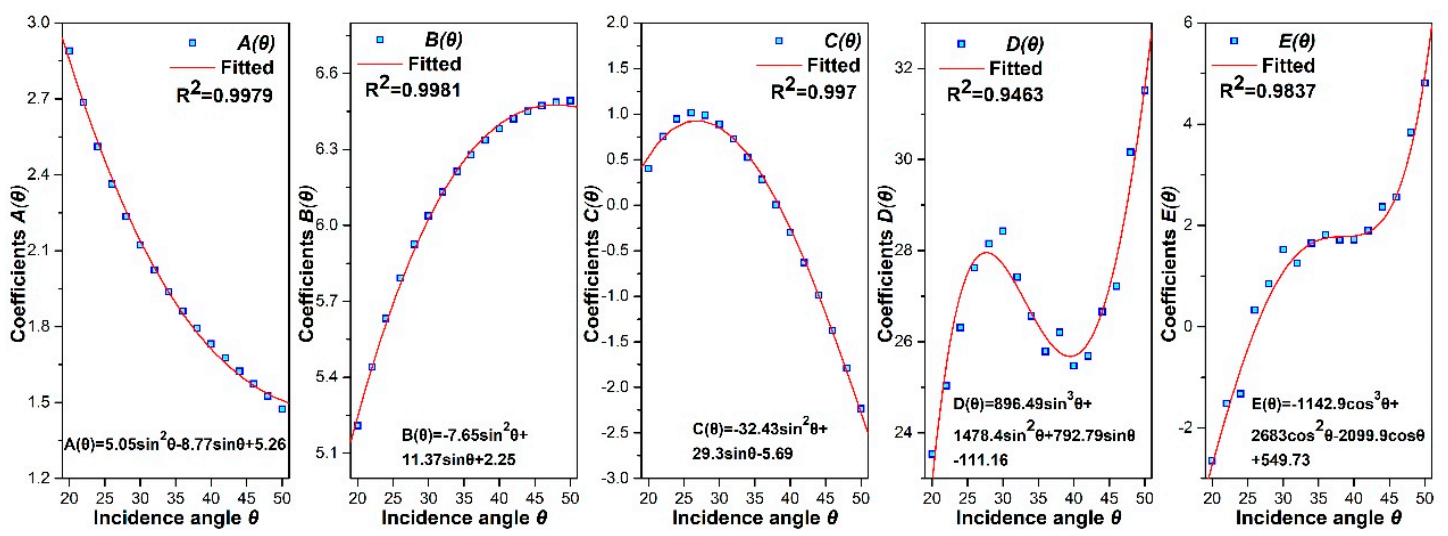

Figure 9. Response of the incidence angle $\theta$ to the function coefficients: $A(\theta), B(\theta), C(\theta), D(\theta), E(\theta)$, while the red curve represents the fitted function.

\subsection{The Local Incidence in the Study Area}

Derived from the data description, the radar viewing angle at the central target of the Sentinel-1A radar images acquired on October 19th, 2017 is $39.24^{\circ}$. Figure 10 shows the inversion result in study area, with strongly differentiated topographic conditions based on the IACM. The spatial distribution of the local incidence angles present heterogeneity caused by the variation of slope and aspect. Specifically, in the Loess tableland, with a relatively flat terrain, the local incidence angles are mostly close to $39.24^{\circ}$ (green color in Figure 10). On the other hand, in the Loess valley, with a large topographic relief, the local incidence angles differ significantly from the radar viewing angle, as shown in orange or blue color in Figure 10.

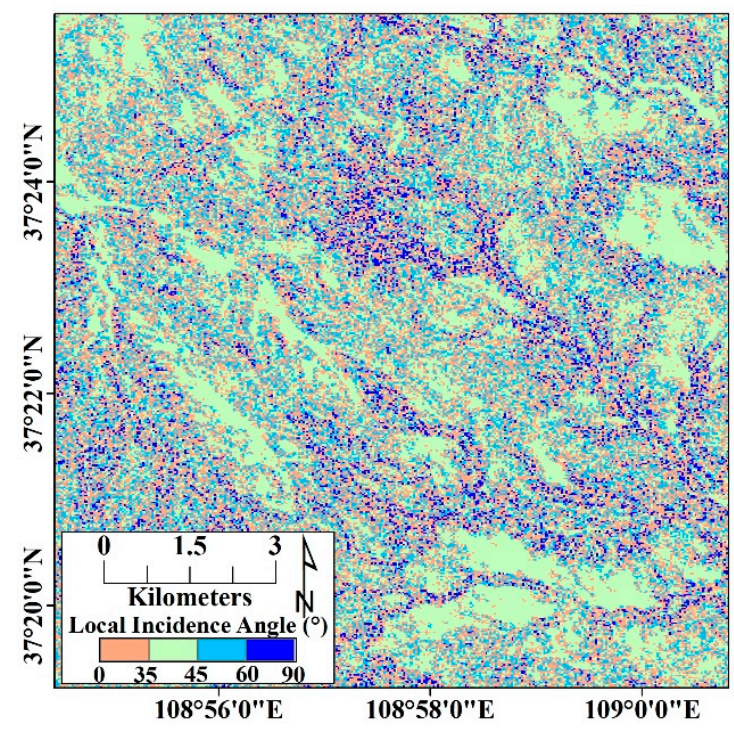

Figure 10. The map of local incidence angles in the study area inverted based on IACM.

\subsection{Soil Moisture Estimation}

After the backscattering coefficients were extracted from SAR images and the local incidence angles were inverted, the estimation of soil moisture status over complex terrain land was computed based on the retrieval model given in Section 3.2. The map of volumetric soil moisture overlaying hillshade graph derived from AW3D30 product is shown in Figure 11, which reveals that land with volumetric soil moisture between $0 \%$ and $20 \%$ is predominant, mostly distributed in the Loess tableland, ridge and hills. Due to the regional dry climate and the strong differentia between evaporation and precipitation, soil moisture in such areas is low. Particularly in the Loess tableland with high 
topography and few vegetation, the soil moisture is between $0 \%$ and $10 \%$. In the Loess gully areas formed by the Loess erosion, soil moisture is higher with volumetric content between $20 \%$ and $40 \%$, largely because of surface water migration via seepage.

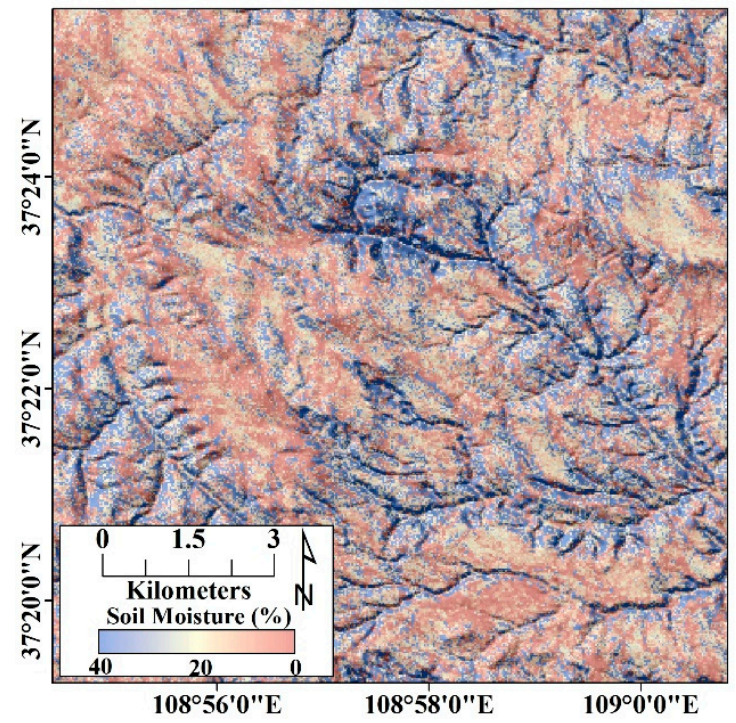

Figure 11. The map of volumetric soil moisture in the study area overlaying hillshade.

\section{Discussion}

\subsection{Reliability Evaluation of Soil Moisture Estimation}

As mentioned in Section 2.1, 43 in situ measurements over the verification area obtained within two hours before the acquisition time of Sentinel-1A data were used as validation data to evaluate the accuracy of the soil moisture estimation in terms of root mean square error (RMSE) and standard deviation of absolute error (SDAE). As a result of validating with in situ measurements, it is worth mentioning that the RMSE of estimation values is $0.963 \%$, indicating a reliable performance of the retrieval methods. Moreover, the SDAE is $0.957 \%$, indicating a small dispersion of the difference between the estimation value and in situ measurements (Figure $12 \mathrm{~b}$ and Table 3). The number of verification sites with absolute errors ( $\mathrm{AE}$ ) between $-0.5 \%$ and $0.5 \%$ is 24 , accounting for $56 \%$, indicating stability of the estimation (Figure 12b).

The in situ measurements were divided into 3 types, including arable land, hill and tableland, according to the topographical condition. Figure 12 suggests that the different topographical conditions have different performances on soil moisture estimation. Firstly, the range of soil moisture observed is adequately representative because the estimated mean of soil moisture over arable land is the highest due to agricultural activities, reached $19.29 \%$, while the estimated means over hill and tableland are $14.14 \%, 13.35 \%$, respectively (Figure 12a). Furthermore, in terms of error evaluation, the finest retrieval takes place in the hill areas, where the SDAE and RMSE are smallest, with values equal to $0.347 \%$ and $0.388 \%$, respectively. In the arable land areas, the SDAE and RMSE are $0.875 \%$ and $0.89 \%$, respectively. The situation in tableland areas seems complex, with $1.386 \%$ SDAE and $1.386 \%$ RMSE (Table 3), due to the sparse distribution of a few low shrubs.

With respect to the roughness parameters, Zribi and Dechambre previously introduced the original roughness parameter $Z_{s}=s^{2} / l$ as a roughness parameter combination [22]. Since the numerical relations are based on sensor parameters and soil conditions in the AIEM, different forms of combined roughness parameter were developed by Yang et al. [63] and Kong et al. [64] over respective soil conditions. Therefore, the comprehensive roughness proposed in this paper is novel but appropriate for reducing the unknowns in the AIEM in the Loess Plateau region from Sentinel-1A. 
Several studies on the soil moisture estimation over the Loess Plateau from SAR have been also reported [64-66]. Specifically, Zhang et al. estimated soil moisture over the western Loess Plateau area with a complicated landscape using ENVISAT ASAR data with VV polarization, and the result was strongly influenced by the terrain variation leading to the invalid estimations in the steep inhomogeneous slope of hill region [66]. Kong et al. retrieved soil moisture over the blown-sand area, namely Mu Us Desert located in the northern Loess Plateau, and the low soil moisture with major volumetric content between 0 and 15\% corroborates our results well [64]. In summary, all the estimated results previously addressed indicated that soil moisture in the Loess Plateau is low.
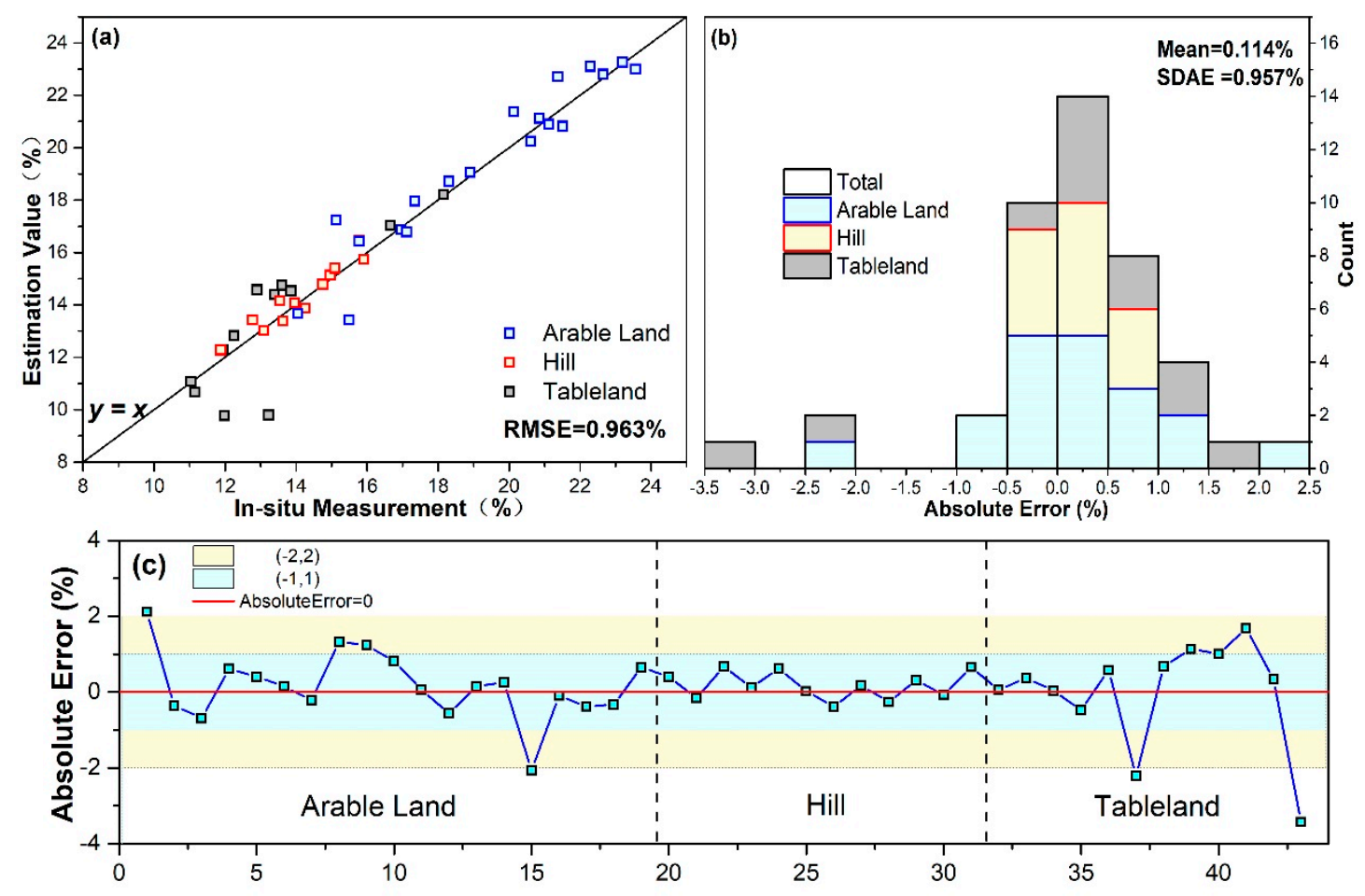

Figure 12. Accuracy evaluation of the estimated results: (a) the comparison between the estimation value and the in situ measurement; (b) the statistical analysis of the absolute errors of soil moisture estimation; (c) the absolute errors of soil moisture estimation in each in situ site with different topographical conditions.

Table 3. The absolute errors statistic of soil moisture estimations on different topographical conditions.

\begin{tabular}{cccc}
\hline Land Type & Mean (\%) & SDAE (\%) & RMSE (\%) \\
\hline Arable Land & 0.162 & 0.875 & 0.890 \\
Hill & 0.173 & 0.347 & 0.388 \\
Tableland & -0.02 & 1.386 & 1.386 \\
Total & 0.114 & 0.957 & 0.963 \\
\hline
\end{tabular}

\subsection{Performance Evaluation of IACM}

The gully fields of the Loess Plateau have several prominent characteristics that are important for soil moisture estimation, such as the semi-arid climate environment and the complex terrain condition. As mentioned in Section 2.1, bare land becomes the major constituent land type, which is attributed to the semi-arid environment, benefiting the retrieval stability on the basis of AIEM simulation. However, the regional terrain is certainly a factor that makes the soil moisture estimation harder, due to the dependence of the retrieval model on the local incidence angle. 
To address this problem, this paper proposed a model, called IACM, for calculating the local incidence angle, thereby enhancing the estimation accuracy. To evaluate the performance of IACM, the volumetric soil moisture was repeatedly estimated under the same conditions except using IACM for the local incidence angle retrieval. The results evidence that coupling IACM and AIEM for soil moisture estimation in gully fields is much more efficient than only AIEM employed (Figure 13). The SDAE of estimation without IACM is $4.82 \%$, which is $500 \%$ larger than that with IACM corrected $(0.957 \%)$. Correspondingly, the RMSE of estimation without IACM is $4.83 \%$, compared to $0.963 \%$ with IACM. As shown in Figure 13, soil moisture estimation over hill areas, which have the most complex terrain of the three topographical conditions, receives the most significant improvements with IACM. Therefore, taking advantage of IACM to retrieve local incidence angle can expand application of quantitative estimation based on microwave backscattering model to the fields with complex terrain.

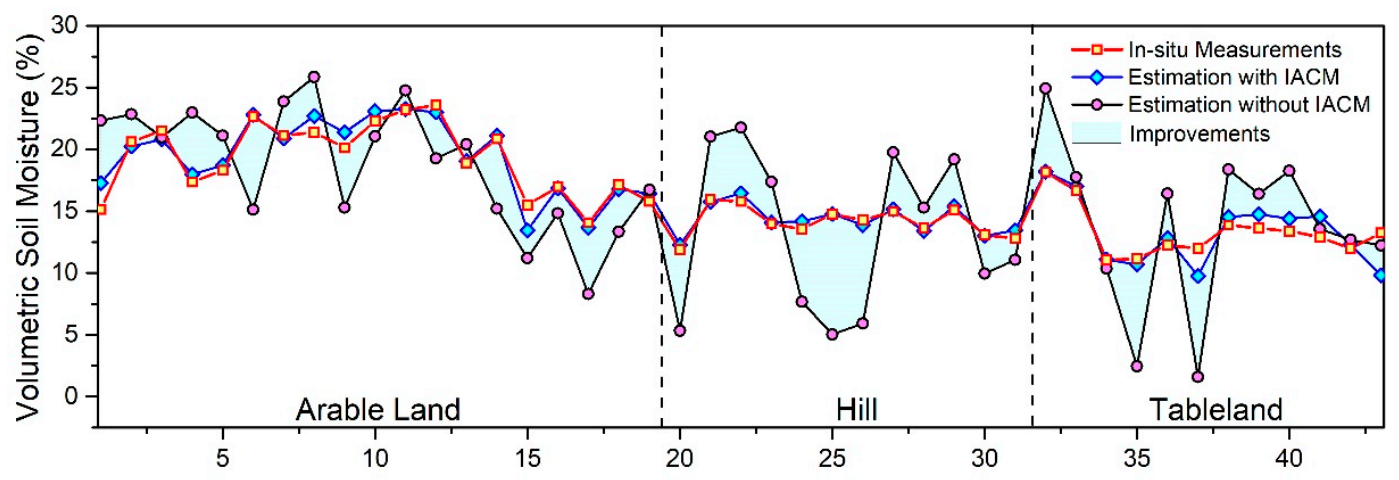

Figure 13. The volumetric soil moisture in each in situ site by different methods under various topographical conditions.

\section{Conclusions}

In this study, we proposed an improved approach to estimate the bare land soil moisture in gully fields of the Loess Plateau from Sentinel-1A dual polarization data, based on the joint use of AIEM and IACM. To address the difficulty in acquiring surface roughness parameters in complicated gullies fields and the ill-posed problems in the retrieval, we adopted SAR images with dual polarization to establish two simulated numerical relations, and united both of them for eliminating the surface roughness parameters of the retrieval model. Additionally, we proposed to use IACM to calculate the local incidence angle and then appended it into the retrieval model to mitigate the influences of uneven terrain.

The results indicated that the overall status of soil moisture in the study area was generally dry, but differed by landform. The estimation accuracy of the improved approach was evaluated using the in situ measurements around the SAR observation time, with total SDAE $0.957 \%$ and RMSE $0.963 \%$, indicating a good agreement between estimations and in situ measurements. Moreover, the improvements of soil moisture estimation promoted by introducing the IACM was evidenced when we compared it to the soil moisture with SDAE $4.82 \%$ and RMSE $4.83 \%$ using AIEM solely. The improved approach developed in this paper demonstrated its utility for the soil moisture estimation, particularly in the fields with complex terrain.

On the basis of this study, our further work will mainly focus on two aspects. One is to extend the soil moisture estimation fields to areas with diversified land cover, instead of just the bare land. The other is to explore the estimated time-series monitoring approaches for multi-temporal SAR images, that is more meaningful to dynamic monitoring and evolution prediction of ecosystem.

Author Contributions: Conceptualization, S.G., S.Z. and H.H.; methodology, S.G.; validation, S.G., X.B. and P.D.; formal analysis, S.G.; investigation, S.G. and Q.Z.; data curation, S.G.; writing-original draft preparation, S.G., P.D. and Y.C.; writing-review and editing, S.G., P.D., X.B., Y.C., S.Z., H.H., Q.Z.; visualization, S.G.; funding acquisition, P.D., Y.C. and Q.Z. 
Funding: This study was funded by the National Natural Science Foundation of China (No.41631176 and No.41804013), the National Key Technologies R\&D Program of China (No.2016YFE0102500) and the Natural Science Foundation of Jiangsu Province, China (No. BK20180666).

Acknowledgments: The authors would like to thank Run Liu, Weibo Wang, Lei An for their help with in situ measurements, Hua Wang for providing the meteorological data, and Yongjun Yang for his excellent encouragements to this work.

Conflicts of Interest: The authors declare no conflict of interest.

\section{References}

1. Xu, W.F.; Yuan, W.P.; Dong, W.J.; Xia, J.Z.; Liu, D.; Chen, Y. A meta-analysis of the response of soil moisture to experimental warming. Environ. Res. Lett. 2013, 8, 044027. [CrossRef]

2. Srivastava, P.K. Satellite soil moisture: Review of theory and applications in water resources. Water Resour. Manag. 2017, 31, 3161-3176. [CrossRef]

3. Peng, J.; Loew, A. Recent advances in soil moisture estimation from remote sensing. Water 2017, 9, 5. [CrossRef]

4. Munoz-Sabater, J. Incorporation of passive microwave brightness temperatures in the ECMWF soil moisture analysis. Remote Sens. 2015, 7, 5758-5784. [CrossRef]

5. Kasischke, E.S.; Melack, J.M.; Dobson, M.C. The use of imaging radars for ecological applications-A review. Remote Sens. Environ. 1997, 59, 141-156. [CrossRef]

6. Li, Z.; Liu, W.Z.; Zhang, X.C.; Zheng, F.L. Impacts of land use change and climate variability on hydrology in an agricultural catchment on the Loess Plateau of China. J. Hydrol. 2009, 377, 35-42. [CrossRef]

7. Feng, X.M.; Fu, B.J.; Piao, S.; Wang, S.H.; Ciais, P.; Zeng, Z.Z.; Lu, Y.H.; Zeng, Y.; Li, Y.; Jiang, X.H.; et al. Revegetation in China's Loess Plateau is approaching sustainable water resource limits. Nat. Clim. Chang. 2016, 6, 1019-1022. [CrossRef]

8. Gao, X.D.; Li, H.C.; Zhao, X.N.; Ma, W.; Wu, P.T. Identifying a suitable revegetation technique for soil restoration on water-limited and degraded land: Considering both deep soil moisture deficit and soil organic carbon sequestration. Geoderma 2018, 319, 61-69. [CrossRef]

9. Yang, Y.J.; Erskine, P.D.; Zhang, S.L.; Wang, Y.J.; Bian, Z.F.; Lei, S.G. Effects of underground mining on vegetation and environmental patterns in a semi-arid watershed with implications for resilience management. Environ. Earth Sci. 2018, 77, 605. [CrossRef]

10. Sanchez, N.; Alonso-Arroyo, A.; Martinez-Fernandez, J.; Piles, M.; Gonzalez-Zamora, A.; Camps, A.; Vall-llosera, M. On the synergy of airborne GNSS-R and Landsat 8 for soil moisture estimation. Remote Sens. 2015, 7, 9954-9974. [CrossRef]

11. Brocca, L.; Tarpanelli, A.; Filippucci, P.; Dorigo, W.; Zaussinger, F.; Gruber, A.; Fernandez-Prieto, D. How much water is used for irrigation? A new approach exploiting coarse resolution satellite soil moisture products. Int. J. Appl. Earth Obs. Geoinf. 2018, 73, 752-766. [CrossRef]

12. Xu, C.Y.; Qu, J.J.; Hao, X.J.; Cosh, M.H.; Prueger, J.H.; Zhu, Z.L.; Gutenberg, L. Downscaling of surface soil moisture retrieval by combining MODIS/Landsat and in situ measurements. Remote Sens. 2018, 10, 16. [CrossRef]

13. El Hajj, M.; Baghdadi, N.; Zribi, M.; Bazzi, H. Synergic yse of Sentinel-1 and Sentinel-2 images for operational soil moisture mapping at high spatial resolution over agricultural areas. Remote Sens. 2017, 9, 28. [CrossRef]

14. Chaparro, D.; Piles, M.; Vall-Llossera, M.; Camps, A.; Konings, A.G.; Entekhabi, D. L-band vegetation optical depth seasonal metrics for crop yield assessment. Remote Sens. Environ. 2018, 212, 249-259. [CrossRef]

15. Yang, Y.J.; Li, Y.; Zhang, S.L.; Chen, F.; Hou, H.P.; Ma, J. Monitoring the impact of fugitive CO2 emissions on wheat growth in CCS-EOR areas using satellite and field data. J. Clean Prod. 2017, 151, 34-42. [CrossRef]

16. Ulaby, F.T.; Dubois, P.C.; van Zyl, J. Radar mapping of surface soil moisture. J. Hydrol. 1996, 184, 57-84. [CrossRef]

17. He, L.; Panciera, R.; Tanase, M.A.; Walker, J.P.; Qin, Q. Soil moisture retrieval in agricultural fields using adaptive model-based polarimetric decomposition of SAR data. IEEE Trans. Geosci. Remote Sens. 2016, 54, 4445-4460. [CrossRef]

18. Liu, Z.; Li, P.; Yang, J. Soil moisture retrieval and spatiotemporal pattern analysis using Sentinel-1 data of Dahra, Senegal. Remote Sens. 2017, 9, 1197. [CrossRef] 
19. Bai, X.; He, B.; Li, X.; Zeng, J.; Wang, X.; Wang, Z.; Zeng, Y.; Su, Z. First assessment of Sentinel-1A data for surface soil moisture estimations using a coupled water cloud model and advanced integral equation model over the Tibetan Plateau. Remote Sens. 2017, 9, 714. [CrossRef]

20. Choker, M.; Baghdadi, N.; Zribi, M.; El Hajj, M.; Paloscia, S.; Verhoest, N.E.C.; Lievens, H.; Mattia, F. Evaluation of the Oh, Dubois and IEM backscatter models using a large dataset of SAR data and experimental soil measurements. Water 2017, 9, 38. [CrossRef]

21. Kornelsen, K.C.; Coulibaly, P. Advances in soil moisture retrieval from synthetic aperture radar and hydrological applications. J. Hydrol. 2013, 476, 460-489. [CrossRef]

22. Zribi, M.; Dechambre, M. A new empirical model to retrieve soil moisture and roughness from C-band radar data. Remote Sens. Environ. 2003, 84, 42-52. [CrossRef]

23. Oh, Y.; Sarabandi, K.; Ulaby, F.T. An empirical model and an inversion technique for radar scattering from bare soil surfaces. IEEE Trans. Geosci. Remote Sens. 1992, 30, 370-381. [CrossRef]

24. Shi, J.C.; Wang, J.; Hsu, A.Y.; Oneill, P.E.; Engman, E.T. Estimation of bare surface soil moisture and surface roughness parameter using L-band SAR image data. IEEE Trans. Geosci. Remote Sens. 1997, 35, 1254-1266. [CrossRef]

25. Dubois, P.C.; Vanzyl, J.; Engman, T. Measuring soil moisture with imaging radars. IEEE Trans. Geosci. Remote Sens. 1995, 33, 915-926. [CrossRef]

26. D’Urso, G.; Minacapilli, M. A semi-empirical approach for surface soil water content estimation from radar data without a-priori information on surface roughness. J. Hydrol. 2006, 321, 297-310. [CrossRef]

27. Vulfson, L.; Genis, A.; Blumberg, D.G.; Sprintsin, M.; Kotlyar, A.; Freilikher, V.; Ben-Asher, J. Retrieval of surface roughness parameters of bare soil from the radar satellite data. J. Arid. Environ. 2012, 87, 77-84. [CrossRef]

28. Zeng, J.Y.; Li, Z.; Chen, Q.; Bi, H.Y. A simplified model of the real part of the soil complex permittivity for soil moisture estimation from SAR image. J. Infrared Millim. Waves 2012, 31, 556-562. [CrossRef]

29. Fung, A.K.; Li, Z.Q.; Chen, K.S. Backscattering from a randomly rough dielectric surface. IEEE Trans. Geosci. Remote Sens. 1992, 30, 356-369. [CrossRef]

30. Chen, K.S.; Wu, T.D.; Tsay, M.K.; Fung, A.K. A note on the multiple scattering in an IEM model. IEEE Trans. Geosci. Remote Sens. 2000, 38, 249-256. [CrossRef]

31. Wu, T.D.; Chen, K.S.; Shi, J.C.; Fung, A.K. A transition model for the reflection coefficient in surface scattering. IEEE Trans. Geosci. Remote Sens. 2001, 39, 2040-2050. [CrossRef]

32. Fung, A.K.; Chen, K.S. An update on the IEM surface backscattering model. IEEE Geosci. Remote Sens. Lett. 2004, 1, 75-77. [CrossRef]

33. Chen, K.S.; Wu, T.D.; Tsang, L.; Li, Q.; Shi, J.C.; Fung, A.K. Emission of rough surfaces calculated by the integral equation method with comparison to three-dimensional moment method Simulations. IEEE Trans. Geosci. Remote Sens. 2003, 41, 90-101. [CrossRef]

34. Wu, T.D.; Chen, K.S.; Shi, J.C.; Lee, H.W.; Fung, A.K. A study of an AIEM model for bistatic scattering from randomly rough surfaces. IEEE Trans. Geosci. Remote Sens. 2008, 46, 2584-2598. [CrossRef]

35. Yamaguchi, Y.; Shinoda, M. Soil moisture modeling based on multiyear observations in the Sahel. J. Appl. Meteorol. 2002, 41, 1140-1146. [CrossRef]

36. Zeng, J.Y.; Chen, K.S.; Bi, H.Y.; Zhao, T.J.; Yang, X.F. A comprehensive analysis of rough soil surface scattering and emission predicted by AIEM with comparison to numerical simulations and experimental measurements. IEEE Trans. Geosci. Remote Sens. 2017, 55, 1696-1708. [CrossRef]

37. Stamenkovic, J.; Guerriero, L.; Ferrazzoli, P.; Notarnicola, C.; Greifeneder, F.; Thiran, J.P. Soil moisture estimation by SAR in Alpine fields using Gaussian process regressor trained by model simulations. IEEE Trans. Geosci. Remote Sens. 2017, 55, 4899-4912. [CrossRef]

38. Amazirh, A.; Merlin, O.; Er-Raki, S.; Gao, Q.; Rivalland, V.; Malbeteau, Y.; Khabba, S.; Escorihuela, M.J. Retrieving surface soil moisture at high spatio-temporal resolution from a synergy between Sentinel-1 radar and Landsat thermal data: A study case over bare soil. Remote Sens. Environ. 2018, 211, 321-337. [CrossRef]

39. Hajnsek, I.; Jagdhuber, T.; Schcon, H.; Papathanassiou, K.P. Potential of estimating soil moisture under vegetation cover by means of PolSAR. IEEE Trans. Geosci. Remote Sens. 2009, 47, 442-454. [CrossRef]

40. Attarzadeh, R.; Amini, J.; Notarnicola, C.; Greifeneder, F. Synergetic use of Sentinel-1 and Sentinel-2 data for soil moisture mapping at plot scale. Remote Sens. 2018, 10, 1285. [CrossRef] 
41. Baghdadi, N.N.; El Hajj, M.; Zribi, M.; Fayad, I. Coupling SAR C-Band and optical data for soil moisture and leaf area index retrieval over irrigated grasslands. IEEE J. Sel. Top. Appl. Earth Obs. Remote Sens. 2016, 9 , 1229-1243. [CrossRef]

42. Baghdadi, N.; El Hajj, M.; Choker, M.; Zribi, M.; Bazzi, H.; Vaudour, E.; Gilliot, J.M.; Ebengo, D.M. Potential of Sentinel-1 images for estimating the soil roughness over bare agricultural soils. Water 2018, 10, 14. [CrossRef]

43. Baghdadi, N.; Cresson, R.; Pottier, E.; Aubert, M.; Zribi, M.; Jacome, A.; Benabdallah, S. A potential use for the C-Band polarimetric SAR parameters to characterize the soil surface over bare agriculture fields. IEEE Trans. Geosci. Remote Sens. 2012, 50, 3844-3858. [CrossRef]

44. Le Hegarat-Mascle, S.; Zribi, M.; Alem, F.; Weisse, A.; Loumagne, C. Soil moisture estimation from ERS/SAR data: Toward an operational methodology. IEEE Trans. Geosci. Remote Sens. 2002, 40, 2647-2658. [CrossRef]

45. Genis, A.; Vulfson, L.; Blumberg, D.G.; Sprinstin, M.; Kotlyar, A.; Freilikher, V.; Ben-Asher, J. Retrieving parameters of bare soil surface roughness and soil water content under arid environment from ERS-1,-2 SAR data. Int. J. Remote Sens. 2013, 34, 6202-6215. [CrossRef]

46. Fatras, C.; Borderies, P.; Frappart, F.; Mougin, E.; Blumstein, D.; Nino, F. Impact of surface soil moisture variations on radar altimetry echoes at $\mathrm{Ku}$ and $\mathrm{Ka}$ bands in semi-arid areas. Remote Sens. 2018, 10, 23. [CrossRef]

47. Leconte, R.; Brissette, F.; Galarneau, M.; Rousselle, J. Mapping near-surface soil moisture with RADARSAT-1 synthetic aperture radar data. Water Resour. Res. 2004, 40, 15. [CrossRef]

48. Kim, J.W.; Lu, Z.; Gutenberg, L.; Zhu, Z.L. Characterizing hydrologic changes of the Great Dismal Swamp using SAR/InSAR. Remote Sens. Environ. 2017, 198, 187-202. [CrossRef]

49. Torres, R.; Snoeij, P.; Geudtner, D.; Bibby, D.; Davidson, M.; Attema, E.; Potin, P.; Rommen, B.; Floury, N.; Brown, M.; et al. GMES Sentinel-1 mission. Remote Sens. Environ. 2012, 120, 9-24. [CrossRef]

50. Hornacek, M.; Wagner, W.; Sabel, D.; Truong, H.L.; Snoeij, P.; Hahmann, T.; Diedrich, E.; Doubkova, M. Potential for high resolution systematic global surface soil moisture retrieval via change detection using Sentinel-1. IEEE J. Sel. Top. Appl. Earth Obs. Remote Sens. 2012, 5, 1303-1311. [CrossRef]

51. Paloscia, S.; Pettinato, S.; Santi, E.; Notarnicola, C.; Pasolli, L.; Reppucci, A. Soil moisture mapping using Sentinel-1 images: Algorithm and preliminary validation. Remote Sens. Environ. 2013, 134, $234-248$. [CrossRef]

52. Wang, H.Q.; Magagi, R.; Goita, K. Potential of a two-component polarimetric decomposition at C-band for soil moisture retrieval over agricultural fields. Remote Sens. Environ. 2018, 217, 38-51. [CrossRef]

53. Pichierri, M.; Hajnsek, I.; Zwieback, S.; Rabus, B. On the potential of Polarimetric SAR Interferometry to characterize the biomass, moisture and structure of agricultural crops at L-, C- and X-Bands. Remote Sens. Environ. 2018, 204, 596-616. [CrossRef]

54. Small, D. Flattening Gamma: Radiometric Terrain Correction for SAR Imagery. IEEE Trans. Geosci. Remote Sens. 2011, 49, 3081-3093. [CrossRef]

55. Bai, X.J.; He, B.B.; Li, X.W. Optimum surface roughness to parameterize advanced integral equation model for soil moisture retrieval in prairie area using Radarsat-2 data. IEEE Trans. Geosci. Remote Sens. 2016, 54, 2437-2449. [CrossRef]

56. Baghdadi, N.; Gherboudj, I.; Zribi, M.; Sahebi, M.; King, C.; Bonn, F. Semi-empirical calibration of the IEM backscattering model using radar images and moisture and roughness field measurements. Int. J. Remote Sens. 2004, 25, 3593-3623. [CrossRef]

57. Dobson, M.C.; Ulaby, F.T.; Hallikainen, M.T.; Elrayes, M.A. Microwave dielectric behavior of wet soil-part II: Dielectric mixing models. IEEE Trans. Geosci. Remote Sens. 1985, 23, 35-46. [CrossRef]

58. Oh, Y.; Sarabandi, K.; Ulaby, F.T. Semi-empirical model of the ensemble-averaged differential Mueller matrix for microwave backscattering from bare soil surfaces. IEEE Trans. Geosci. Remote Sens. 2002, 40, 1348-1355. [CrossRef]

59. Oh, Y. Quantitative retrieval of soil moisture content and surface roughness from multipolarized radar observations of bare soil surfaces. IEEE Trans. Geosci. Remote Sens. 2004, 42, 596-601. [CrossRef]

60. Oh, Y.; Hong, S.Y.; Kim, Y.; Hong, J.Y.; Kim, Y.H. Polarimetric backscattering coefficients of flooded rice fields at L- and C-bands: Measurements, modeling, and data analysis. IEEE Trans. Geosci. Remote Sens. 2009, 47, 2714-2721. [CrossRef]

61. Burrough, P.A.; Mcdonnell, R.A. Principle of Geographic Information Systems; Oxford University Press: New York, NY, USA, 1998; Volume 12, p. 190. 
62. Ye, X.; Kaufmann, H.; Guo, X.F. Landslide monitoring in the Three Gorges area using D-InSAR and corner reflectors. Photogramm. Eng. Remote Sens. 2004, 70, 1167-1172. [CrossRef]

63. Yang, L.P.; Li, Y.F.; Li, Q.; Sun, X.H.; Kong, J.L.; Wang, L. Implementation of a multiangle soil moisture retrieval model using RADARSAT-2 imagery over arid Juyanze, northwest China. J. Appl. Remote Sens. 2017, 11, 036029. [CrossRef]

64. Kong, J.L.; Yang, J.; Zhen, P.P.; Li, J.J.; Yang, L.P. A Coupling Model for Soil Moisture Retrieval in Sparse Vegetation Covered Areas Based on Microwave and Optical Remote Sensing Data. IEEE Trans. Geosci. Remote Sens. 2018, 56, 7162-7173. [CrossRef]

65. Hu, D.; Guo, N.; Sha, S.; Wang, L. Soil Moisture Retrieved Using Radarsat-2/SAR and MODIS Remote Sensing Data in Vegetated Areas of Loess Plateau. Remote Sens. Technol. Appl. 2015, 30, 860-867. (In Chinese)

66. Zhang, T.T.; Wen, J.; Su, Z.B.; van der Velde, R.; Timmermans, J.; Liu, R.; Liu, Y.Y.; Li, Z.C. Soil moisture mapping over the Chinese Loess Plateau using ENVISAT/ASAR data. Adv. Space Res. 2009, 43, 1111-1117. [CrossRef]

(C) 2019 by the authors. Licensee MDPI, Basel, Switzerland. This article is an open access article distributed under the terms and conditions of the Creative Commons Attribution (CC BY) license (http://creativecommons.org/licenses/by/4.0/). 